\title{
Multimedia functions of MMO games
}

\author{
Winton Afrić \\ University North \\ Trg dr. Žarka Dolinara 1, Koprivnica, Croatia \\ wafric@unin.hr \\ Vjekoslav Afrić \\ Faculty of Humanities and Social Sciences, University of Zagreb \\ Ivana Lučića 3, Zagreb, Croatia \\ vafric@ffzg.hr
}

\section{Summary}

This paper is a research of functions of multimedia impacts of MMO games stemming from the analytical framework of J. A. DeVito's functions of Mass Communication. In this paper the analytical concepts of DeVito's theory are applied to a qualitative analysis of the most popular, most played and most represented MMO games, taking into account a so called pattern of intensity, to point out new functions and impacts of MMO games. Our qualitative research showed that the functions of MMOs although comparable to the theoretical framework we started from, create a new theoretical model that discovers specific functions with specific impacts exclusive to MMO games which in the end only share their name and heritage with the theoretical frame we started from.

Keywords: Multimedia functions, MMO games, Multimedia impacts,

\section{Introduction}

Since the new millennium the multimedia that is internet has become ever more important, encompassing other media and becoming the prime communication means of today. One of the most complex and interesting types of multimedia is that of massive multiplayer online games. The growing amount of players and the growth of the games industry is a clear indicator of the contemporary trend - the audiences are no longer satisfied with active and/or linear multimedia, instead they want interactive non-linear multimedia to satisfy their various needs. The development of internet as a means of communication and a network for sharing information, commercial or otherwise, has slowly shifted us as the audience/ receivers into an interactive role. Instead of being offered different types of media we are accustomed to "taking charge" and creating our own communication experiences. What better way to cater to this experience then to use games. The difference between MMO games and their other offline computer games is in the forming of a new online society within the diegetic frame of the online world of an MMO game. This society forms all kinds of diegetic and ex- 
tra diegetic communication/ interaction in which any individual can take part. (W. Afrić, V. Šimović, M. Milković, "The sense of (RPG) Role Playing Games Systems" 2013.) So instead of offering narratives as film, newspapers, or television MMO games offer settings with different rules (structural and processual code) and let players forge their individual experiences interacting with each other and the game world. This paper will therefore focus mostly on MMORPGs since the societal structure and relations are much more complex and elaborate in MMORPGs than in other MMO games. Granted, lots of MMO games have RPG elements which may be important for the games structure so it would be unfair to say we focus only on MMORPGs.

\section{Background research}

For the purpose of this analysis we view multimedia as a system of different communication media which function as a whole. In this context any form of communication which involves multiple media (or multiple channels) is multimedia, so interpersonal communication, group communication; public and mass communication are all different types of multimedia. Different types of technology which enable differing multimedia are only extensions of ourselves (McLuhan, 1964) in this process of multimedia communication and add themselves to the total capacity of communication we possess. This technology enables new structural codes which, added onto the old structural code system, form new different types of processual code and behavior and in turn form new communication patterns and new experience. (J. D. Johansen, S. E. Larsen, "Introduction to Semiotics", 2000.) We have to point out that when we mention communication we are referring to all types of communication but mainly all different types of audio and visual code, followed thirdly by tactile communication which in MMO games translates roughly to muscle memory, and coordination of movements that enables us to play and fulfill various win conditions. There are rare games today in which communication through the tactile is very important. One such example is "Brothers: A Tale of Two Sons" (Starbreeze studios, 2013). Brothers has a section where the two brothers must climb a cliff and the controls make your hands start to hurt from having to hold and press different buttons, thus immersing you in the experience of "hands hurting from hanging for your life".

As the multimedia of choice has changed for many so did the structure of their multimedia experience and the impacts this multimedia has on its audience. It is safe to say that this led to a change to many of the functions multimedia has today as well as some new functions. We will describe the contemporary functions of MMO multimedia by looking at mass communication functions, choosing a rather extensive list of mass communication functions, proposed by J. A. Devito $(1982,526)$. DeVito analyzes mass communication impacts through nine factors where he tries to envelop both good and bad influences of media and how they affect audiences. This rather large list of factors is particu- 
larly interesting because it offers a thorough analytical framework. It shows numerous ways in which mass media affect our everyday life, and we find it very suitable to analyze how MMOs affect our everyday lives. Not all games have all factors equally represented, nor are all factors equally important, but this extensive list is necessary so that we can analyze many different types of MMOs and their different impacts. We have taken the approach of looking at mass multimedia of contemporary MMOs trough the factors that DeVito proposes and analyze how those factors are applicable to the multimedia of MMO's. We have chosen to do a qualitative research of the most popular MMO games with RPG elements. We have selected games using an intensity pattern firstly taking into account games that are most popular, most recent and most updated but we also looked at games featuring different monetization models, games with strong history (and therefore significant audience), and games exploring different / new play styles and methods. In this way we have analyzed games that cover all different player types and cover the largest player base of over 30 million players playing these games on a daily basis. Regarding player types, the time investment differentiates the casual, the serious and the die-hard elite, and the type of activity differentiates the explorer, the achiever and the power gamer, or the soloist and the group player. Most of these different categories stem from the more traditional difference in player preferences proposed by Blacow (1980) called the "Fourwald Way taxonomy" which differentiates the Wargamer, Powergamer, Storyteller and Roleplayer. The MMOs we used in this analysis are: Guild Wars 2, World of Warcraft, Dragon Prophet, Wildstar, Diablo 3, Path of Exile, Grim Dawn, Heroes of the Storm, League of Legends, Dota 2, Dungeons \& Dragons Online, TERA, Lord of the Rings Online, Guild Wars, Torchlight 2, StarCraft 2, Heartstone, Hex, MtG Online. In the rest of the paper we will go through the different factors of the multimedia of MMO's and their features.

\section{The first function of Multimedia: Entertainment}

We can all agree that most games exist first and foremost for entertainment purposes. The entertainment of MMO games is different to other more traditional forms of multimedia entertainment in the sense that it is first and foremost interactive, it forms a unique experience and in many cases strives to give players more control over how they spend their time entertaining and how much time they spend. Most MMO games today especially MMORPG games go through great lengths to deliver an experience where each player and group of players feels like a central piece in the story (GW2, WoW, D3 etc.). Their choices have significant impacts on the world around them. Players develop their characters immersed into various roles and have a unique perspective on the world, one that will change if they change their character. This type of story-forming experience is one of the most entertaining aspects of MMO games. The entertainment boils down to two opposing types of play PvE (Player 
versus Environment) and PvP (Player versus Player). PvE focuses on player collaboration against more or less pre structured encounters where win conditions range between certain levels of character power needed along with player knowledge and skill. This type of play is very entertaining when players and groups win at these encounters receive various rewards and acknowledgements and advance in the game (Raids, Dungeons, Open World Boss encounters, BAMs etc.). PvP pits players and groups of players against each other and is more about skill and spontaneous player reaction then PvE (Battlegrounds, Duels, Arenas, and Open World PvP etc.). The satisfaction here comes firstly from besting other players and secondly from rewards won inside the game. Ultimately there are different types of players which strive for different types of satisfactions and find different activities entertaining. Game developers try to cater to all of the different player types and make aspects of the game that are entertaining to all of them, as well as specific fragments made for each individual group. Different types of players with different preferences can include different players in accordance of how much time they spend playing the game or what activities they prefer when playing the game. As MMO's develop they try to incorporate new entertaining and unique ways to satisfy each individual player type. For instance "Guild Wars 2" (ArenaNet, NCSoft 2012) introduced Vistas as a means to entertain the explorer. Players need to find secret and hidden routes to difficult-to-reach places and once they get there players get to see an animation of the panoramic view from that place, that beautiful vista. Blizzard are introducing a new way to cater to Storytellers in their (currently in beta development patch for the) "Diablo 3" (Blizzard 2012) where the various ways to play the game are now structured into a unique character journey which becomes a players own character story.

\section{The second function of Multimedia: Education}

The multimedia of MMO games educates us in various ways. This type of education although non-formal stretches through various fields and practices. Surely the most important education we receive from RPG in general is the fact that we learn to recognize different types of societal roles and learn to understand differing perspectives of these roles. When we tie roles to attributes such as race, gender, age, intellect, charm etc. we understand different characters as different constellations of attributes, with unique perspectives stemming from those attributes. Therefore playing we learn about differences in a way where we see typically problematic differences in race or gender roles as variance in attributes and perspectives and learn to tolerate differences and acquire a multicultural frame of mind. This type of sensitivity training is also true for experiences which stem from roleplaying different roles and learning what is their perspective and diegetic frame. Here roleplaying educates us about Empathy, Equality, and Openness. MMORPG games are more narrow and specific when looking at these educational aspects due to the fact that most of the diegetic 
frame is communicated to us through the multimedia of the game system and is therefore limited by the scope of the game. In MMORPG games we learn about roles through the perspective of our class or character role, we learn about player power dependence (the given matrix, effective matrix and dispositional matrix) (R. West, L. Turner, "Introducing Communication Theory", 2007). We learn how to treat other roles, and other players and what to expect from them. Each MMO is in part a simulation of real world relations and we learn about causal processes and behaviors which correspond to real life situations. The simulation and the education process can be more or less obvious (we can play in a real world environment, or in a real world society structure, we can use real world military strategy or tactics, fly a real life plane etc.) We also learn about the virtual component, in MMORPGs especially about the virtual society. What values, opinions and rules the virtual society judges to be just and valid.

\section{The third function of Multimedia: Conference of Status}

Typically this function has to do with recognizing important individuals and those individuals have been given lots of media exposure. In MMO multimedia we don't only recognize important exposed individuals we can learn what it is that makes them important. Becoming exposed has also became interactive and a matter of player preference and desire. The most important individuals here are skilled players as well as the so called streamers and enthuse journalists. All of those have lots of media coverage which comes in various extradiegetic forms, but they are all focused on the game. Examples of these forms are game forums, YouTube channels, web sites, facebook \& twitter profiles, reddit posts, twitch streams etc. be it educating players about the game, doing commentary while playing or making shows with discussions about the game world. Many of these have players following their channels and streams and paying them monthly to create game related content and thus playing and creating new multimedia content about a game or games in fact becomes their job. Since any player or group of players can make their own YouTube channel, a website or join Twitch or another service and stream while playing, anyone can take steps to become a celebrity and earn status. In this way the media not only tells us what is important but it also shows us what steps we can take to become important. However it is not only individuals that can be recognized as important, through the celebrity created content we can recognize game related concepts and behaviors as important and less important. Game developers keep a close eye on this type of content as it helps them determine on which things the public is concentrated, why it is concentrated on them, whether that is positive or negative for the scope of the game and this often leads to changes in the game. The question that remains is would the changes occur if the media has not focused on this content or not? 


\section{The fourth function of Multimedia: Reinforcement}

When we speak of reinforcement we mean the process of strengthening ones beliefs, attitudes, values and opinions. The multimedia of MMO games does this in various ways. Firstly as games develop they will reinforce us to expect and display certain types of behavior within games and to develop certain values and opinions towards various aspects of the game and games in general. Reinforcement in MMO's works firstly for concepts learnt within the game. So players develop behaviors towards different types of players, value different player behaviors differently and they develop a sense of what they want from a game. One of the popular, major values that is constantly reinforced is how much time should an individual spend playing? It is hard to get people that are not interested in playing a game to play it. But getting people that play it to play more is much easier. Also getting players that enjoy in one type of game activity to try another game activity is also done by reinforcement. Another popular topic is how much should games cost, and is it ok for games to charge a monthly fee to be able to play them? How large should this monthly fee be? Is it ok that a game is free but has an Item mall where you can spend real money to buy advantage through Power-ups and Quality of Life changes? General different opinions regarding the answers to these questions can be found all over the internet and are reinforced with both diegetic and extradiegetic means. A popular enthuse journalist "TotalBiscuit, The Cynical Brit" stated that it is relatively easy to determine how much one wants to pay for a video game, be it monthly or otherwise and he offered the following reasoning. Since people play games to satisfy various needs but mostly to have fun it is easy to compare it to costs of going to a movie or the theater. In Croatia an average movie ticket costs $4.2 \mathrm{Eu}-$ ros and it offers 2 hours of entertainment. A digital copy of Diablo 3 for instance costs 39.99 Euros and the first play trough offers over 20 hours. So they seem roughly the same. However given the nature of the game most players invest hundreds of hours over the years exploring different options with different characters and that's not even mentioning free content that is being constantly developed and patched to the game. Playing Diablo 3 thus becomes 10 times cheaper than going to the movies. We should also take Wilbur Schramm's formula where he elaborates the probability of the audience to choose a particular media into account (W. L. Schramm," Men, messages, and media: A look at human communication", 1973). Schramm proposes that: Promise of reward / Effort required $=$ Probability of selection. It is important to note that the Promise of reward takes into account both immediate and delayed rewards, which are in fact satisfactions of various needs. It is easy to deduce that it takes less effort to play a computer game than to go to a movie. Looking at these reasoning's we can understand why it is easy for MMO multimedia to reinforce audiences to spend money on games, game items, game time etc. 


\section{The fifth function of Multimedia: Activation}

The goal of each MMO game is to get people to play it. Most successful games do this rather well. Since people have limited time to spend on any activity choosing to play always comes with a cost and when we think how many games out there compete for player attention it becomes clear that there is a media war for attention going on. Most games of the same genre are aware of what the other games developers are doing. When is any particular patch day, any expansion etc. But more than that MMO's evolve with time which is done by gathering as much feedback from the player community as possible. The recent arrival of early access games that become playable in alpha and beta states and frequent open betas where players test new game content activate players not only to play but to take part in creating this next bit of content to the game they love and invest so much in. One of the greatest challenges of game development is to maintain the balance of focus - where the game is going and scope - what the player community wants from the game, and all the while keep the player base active and playing. Activating players to do various activities within the game world is also crucial for any successful MMO game specially RPGs. Developers think of new ways to activate players to visit certain places in the game world (gather in one specific area over another), play certain content (map, dungeon, boss encounter), play in a certain way (heal, group, raid, pvp etc.) but also activate players to write about the game, make YouTube videos, Fan art, Discussions, Fan web sites etc.

\section{The sixth function of Multimedia: The Creation of ties of Union}

The multimedia of MMO games creates stronger ties of union than any form of mass communication before. What is more important the ties of union created by television and films are artificial but ties of union created in MMO games are real and they compete with different types of belonging from outside of the game-world. While playing in virtual societies we create groups, clans, guilds etc. which become the fundamental social institution of the game world. These ties of union revolve around game activities and primarily diegetic communication but can step out of the diegetic frame of the game. Players fulfilling various roles within these groups achieve together and form unique experiences within the game world which forms real and strong ties of union with common interests, values, beliefs, opinions and attitudes. These ties of union are strengthened trough play time within the group and trough achieving various win conditions together as a group. They strengthen trough common activities, education, reinforcement, the building and conference of status, and ultimately having fun as a group. It is common for long standing guild members to develop meaningful relationships, become close friends outside of the game and do various activities in the real world. Other types of multimedia have been tied with the function opposite of Creating Ties of Union, that of Privatization (J.A.DeVito, "Communicology" 1982). That concept refers to an individual shutting themselves 
into their private world conferred by the media and focusing on problems that don't involve any social ties. The multimedia of MMO games doesn't suffer from that kind of problem being oriented towards player interaction and communication. We may however use the term Privatization to describe players which become more interested with the game world and game problems than the real world. Such players spend over 10 hours per day playing a certain game or games. This can naturally be a bad thing but can however lead to players becoming professional gamers and E-Sports develop at an amazing rate. In 2014 professional gamer Chen, Zhihao has earned \$1,112,281.00 playing Dota 2 and it is common for professional gamers to earn several hundred thousands of dollars per year.

\section{The seventh function of Multimedia: Persuasion}

This function has primarily to do with the change in the audience's behavior. Persuasion goes hand in hand with Reinforcement. It can be seen as reverse or extreme reinforcement where instead of strengthening ones belief, opinions, values and attitudes they end up being changed. Traditional mass media were quick to induce changes of a smaller scale but larger changes like political preferences, religious attitudes or social commitments were very hard to change. MMO's are however another story. As most MMO's form virtual societies and groups they bring new social commitments and they often force choice upon the player of how to prioritize their own social obligations. The rewards of MMO's are frequently more immediate than those of sports, education or most real life commitments so younger people are quick to institute social commitments of games into their everyday life. This can become highly problematic as players can be easily persuaded to play instead of doing a plethora of other things and in turn they can sever their real life ties and substitute them with ties from the game world. Political and religious attitudes are often besides the point and not directly influenced by games but as people invest more and more time into a game they get more and more disconnected with political and religious developments in their community and the world. Thus the importance of their political and religious attitudes will surely lessen. The way MMO's are structured today makes them easy to persuade players to invest more and more of their life into the game, the rewards offered are wide in scope, ranging from immediate character advancement and power, immediate social status that comes with progress and skill, and the promise of becoming a successful streamer or professional gamer. The problem is that most games will occupy more than $50 \%$ of one's waking hours in order to achieve this promise and therefore change a person's entire life. Obviously there is high risk of ruining one's own life when choosing this road. 


\section{The eighth function of Multimedia: Providing Ethics}

Traditional mass media have provided audiences with ethical systems for decades. This collective ethic was formed through various information's made public, and overall media coverage of various events. This kind of coverage forces the audience into a degree of action against something that cannot be tolerated, or for something that the public suddenly approves. It seems that MMO's reflect this behavior but mostly centered on problems that have to do with games. It has little to do with religion, sexuality and race but can have lots to do with similar concepts if they belong to the game world. Factions can express hate towards one another, classes and character types can be labeled inferior and create different concepts of right and wrong. Most games teach us how to treat other players, especially new players. Many games (particularly Mobas or FPS games) have very toxic communities which will insult new or less skilled players to that extent that it may lead to people stop playing. One of the great examples of $\mathrm{MMO}$ ethics is the great debate among player communities on the theme of DLC (downloadable content). For years various game developers created DLC as free additions to the game with the goal of keeping the player base active. But as the games switched to different monetization models DLC became a way of monetizing the game and creating a successful business model. New areas such as maps, new items, new encounters, new characters, new cosmetic items or appearance changes etc. all represent various forms of DLC which is popularly monetized. Most DLC are expendable as to persuade players to keep buying them. The problems arise when we question whether or not these DLC are needed to get a good experience of the game and how much they cost. The public verdict as of now, which is present in forums, game chat, YouTube shows by enthuse journalists and such, is that DLC is fine as long as it doesn't give a player a significant advantage in the game making it mandatory. Cosmetic DLC only is generally fine since it gives players no real advantage but it can be frowned upon if it is "day1 DLC". Day1 DLC is DLC which is available for purchase on the day the game is released. This is deemed non ethical because if it is developed already why isn't it in the game we bought? If the game is however free, than it is acceptable that there is day1 DLC of the cosmetic nature.

\section{The ninth function of Multimedia: Narcotization}

In traditional mass media this function was about audiences mistaking knowing about problems for doing something about them. Narcotization in MMO's is similar in that it lets game related problems substitute other life problems and drugs players into inactivity in all non game related fields. Character progress, achievements, guild progress, rank and status, team standing, ones place on a ladder, personal score etc can become problems of such importance that they shadow ones job, school and any other obligations. People may still go to their job and attend school but they will use every minute they can to focus on the 
problems from the game. They will watch videos from the game, write on forums, and try to stay connected to the game world in any way they can until they get the chance to play and tackle their primary concerns. Often people can be in the game doing nothing for hours because they are waiting for a group activity to start, or trying to find a way to get satisfaction trough any kind of advancement. Games can in this way become highly addictive.

\section{Conclusion}

This analysis shows that we have to keep the various functions of MMO games into account when choosing them. These various functions are not separate but they work together in a package. Games will activate players into playing, reinforce certain behaviors, promise rewards and persuade them to go after those rewards. They will be entertaining and fulfilling, create strong ties of union with other players inside the discourse of the game world and create fertile ground to narcotize the players getting them addicted. More importantly we cannot sit idly while our children choose games they will play not knowing the structure of the factors of that game. We need to be involved and understand the factors of various games and what their impacts are. The trend is that most games today have an expert level of maximum rewards which is reserved only for the professional players, the die-hard elite. The promise of those rewards the games tease us with is not realistic for most players and the question remains what to do with the allure they pose, and the potential hazard the road to that promise means? Is it a question of ethics to find a way to separate professional gaming from casual gaming? It is our obligation as parents, teachers, and elders to step in reshape and redefine the road which MMO games of today represent. MMO games today influence our society and shape our youth and it is our obligation to stop sitting idly while this process is going on. We have to explore and establish how we want the games to be tied into our society and what kinds of rewards do we want to attribute games with. We have to define where that thin line between entertainment and work, leisure and obligation is. It is high time to intervene and redefine what it means to be n00b and what it means to be pr0!

\section{References}

Afrić, Winton; Šimović, Vladimir; Milković, Marin. „The sense of (RPG) Role Playing Games Systems“. Koprivnica: Medijsko Sveučilište. 2013.

Athique Adrian. „Digital Media and Society: An Introduction“. Polity, 2013.

DeVito, Joseph A. "Communicology”. New York: Harper \& Row, 1982.

Fine, Gary A. ,Shared Fantasy Role playing games as social worlds“. University of Chicago. 2002.

Johansen, Jorgen D.; Larsen Svend E. „Uvod u semiotiku“ Zagreb: CroatiaLiber, 2000.

McLuhan, Marshall; Fiore, Quentin. „The Medium is the Massage“. Gingko Press; 9th edition, 2001.

McLuhan, Marshall; Gordon, Terrence W. ,Understanding Media: The Extensions of Man : Critical Edition“. Gingko Press; Critical Edition, 2003.

Schramm, Wilbur L. "Men, messages, and media: A look at human communication", New York: Harper \& Row, 1973.

West, Richard; Turner, Lynn. "Introducing Communication Theory”, McGraw Hill. 2007.

Williams, Patrick J.; Hendricks, Sean Q.; Winkler, Keith W. „Gaming asa Culture: Essays on Reality, Identity and Experience in Fantasy Games“. McFarland \& Company, Inc. 2006. 